\title{
Evaluating the Role of Soil Variability on Potential Groundwater Pollution and Recharge in a Mediterranean Agricultural Watershed
}

\author{
Antonio Coppola, Alessandro Comegna, G. Dragonetti, \\ and Lorenzo De Simone
}

\begin{abstract}
Regional-scale studies on groundwater vulnerability assessment of non-point source agrochemical contamination suffer either from no evaluation of uncertainty in data output, in that of qualitative modelling, or from prohibitively costly computational efforts, in that of deterministic modelling. By contrast, a methodology is presented here which integrates a solute transport model based on transfer function (TF) and a geographic information system (GIS). The methodology (1) is capable of solute concentration estimation at a depth of interest within a known error confidence class, (2) uses available soil survey and climatic and irrigation information and requires minimal computational cost for application and (3) can dynamically support decision-making through thematic mapping. Raw data (coming from different sources) include: i) water table depth, ii) soil texture properties, iii) land use, and iv) climatic information with reference to a study area located in southern Italy. Such information has been then manipulated in order to generate data required for the subsequent hydrological modelling. Simulated breakthrough curves were generated for each soil textural class. They are texture-based travel time probability density functions $\left(\mathrm{TF}_{\mathrm{tb}}\right)$, describing the leaching behaviour of soil profiles with similar soil hydrological properties. The latter, in turn, were estimated by indirect estimation techniques such as pedotransfer
\end{abstract}

\footnotetext{
A. Coppola $(\triangle)$

Department of European and Mediterranean Cultures-Architecture, Environment, Cultural Heritage (DiCEM), Hydraulics and Hydrology Division, University of Basilicata, Matera, Italy e-mail: antonio.coppola@unibas.it
}

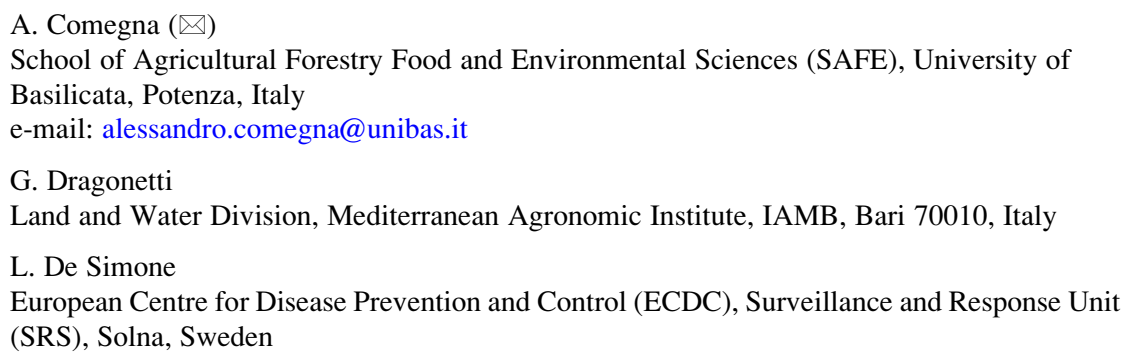


functions (PTFs) to overcome the trouble of intensive in situ and/or laboratory determinations of soil hydraulic and hydrodispersive properties, which are generally lacking for regional-scale studies. Results showed large differences in the magnitude of the different travel times and related uncertainties among different profiles. The lower or higher vulnerability was found to be mainly related to the average silt content of the soil profiles.

\section{Introduction}

Non-point source (NPS) pollution in the vadose zone (simply defined as the layer of soil extending from the soil surface to the groundwater table) is a global environmental problem. The knowledge and information required to address the problem cross several technological and sub-disciplinary lines: spatial statistics, geographic information systems (GIS), hydrology, soil science and remote sensing (Corwin 1996; Corwin et al. 1997; Coppola et al. 2014).

As discussed by Stewart and Loague (2003), the main issues encountered in NPS groundwater vulnerability assessment are the large spatial scales, the complex processes that govern fluid flow and solute transport in the unsaturated zone (Comegna et al. 2010; Coppola et al. 2011), the absence of unsaturated zone measurements of diffuse pesticide concentrations in 3D regional-scale space (as these are difficult, time-consuming and prohibitively costly) and the computational effort required for solving the nonlinear equations for physically based modelling in heterogeneous media at regional scale (Coppola et al. 2014). This results in significant simplifying assumption in NPS contaminant leaching models.

Currently, existing regional-scale leaching models can be grouped into four main categories, ranging from qualitative models that rely on index and overlay techniques, over simple drainage algorithms, to stream tube models coupled to process-based numerical simulations (Stewart and Loague 2003; Coppola et al. 2014). The large datasets of physical factors involved in the leaching process required for regional-scale studies limit the use of deterministic methods that would result in more realistic estimates of solute concentration. Besides, the use of overlay models encounters less computational and data lacking issues, though resulting in relative output information in terms of risk factor.

As a compromise solution, an approach is presented here which is based on coupling of texture-based transfer function $\left(\mathrm{TF}_{\mathrm{tb}}\right)$ and GIS modelling. $\mathrm{TF}_{\mathrm{tb}}$ are texture-based travel time probability density functions describing a characteristic leaching behaviour for soil profiles with similar soil hydraulic properties. They actually represent the result of an upscaling procedure applied to Jury's transfer function model (TFM) (Jury and Roth 1990).

GIS represents a spatially enabled database management system (DBMS) that is able to depict real-world geographic features of relevance to the leaching process, 
serving both as a baseline data depot for hydraulic modelling and a final gateway for output representation and interactive delivery.

With these premises, the main objective of this study was developing a regionalscale simulation methodology for vadose zone leaching that is capable of overcoming the limits of both fully deterministic and fully qualitative models in that it relies on easily available and accessible data and on affordable computational efforts and finally offers quantitative answers to groundwater vulnerability to agrochemical leaching at regional scale within a defined confidence interval.

This result was pursued through (1) the design and building of a spatial database containing environmental and physical information regarding the study area, (2) the development of the $\mathrm{TF}_{\mathrm{tb}}$ for layered soils and (3) the final representation of results through digital mapping.

One side GIS modelled environmental data in order to characterise, at regional scale, soil profile texture and depth, land use, climatic data, water table depth and potential evapotranspiration. On the other side, such information was implemented in the development of a set of $\mathrm{TF}_{\mathrm{tb}}$, each describing the leaching behaviour of soil profiles with specific hydraulic properties. The latter, in turn, were estimated by area-specific pedotransfer functions developed on our own texture-hydraulic properties datasets coming from several sites in the investigated area. A wide area (about 12,000 ha) in the Metaponto plain in southern Basilicata, Italy, was completely characterised by a pedological point of view by digging several soil profiles. The textural properties of soil horizons of each soil profile were converted to the corresponding hydraulic properties by using a PTF specifically calibrated for the soils of the area (mainly silty loam, silty and silty clay). The solute travel times to water table for specific soil profiles were then imported back into GIS, and finally estimation of groundwater vulnerability for each soil unit was represented into a map.

\section{Materials and Methods}

\subsection{Study Area}

For this study, the area of interest was subbasin of Metaponto agricultural site, located in southern Basilicata, Italy, across the municipalities of Policoro, Scanzano Jonico, Montalbano Jonico and Pisticci, approximately 11,698 ha in size and crossed by two main rivers, Sinni and Agri, and from many secondary water bodies. Figure 1 shows the location of the study area.

Topographically, the area is characterised by fairly distinct variations in elevation in the western part of the basin, away from the coast, and extremely flat terrain in the nearshore portions of the basin, to the south and east. The main soils in the area are the "soils of the alluvial plains" and the "soils of the Ionian coastal plain". The soils of the alluvial plains are those formed along the fluvial channels of the 


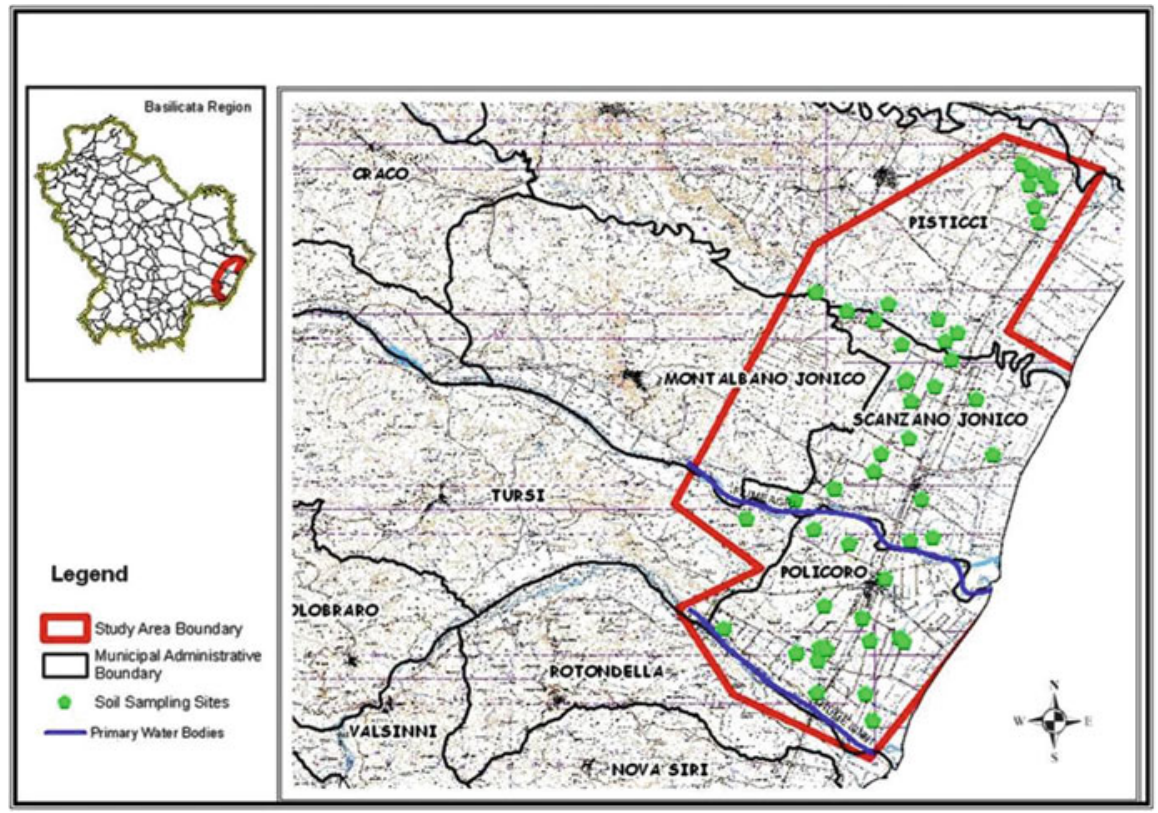

Fig. 1 Study area overview (circles indicate soil profile sites)

rivers crossing the area. Therefore, they are soils on alluvial and lake deposits, with variable grain size from clayey to stony. The soils of the Ionian coastal plain consist of marine deposits of different ages, from Pleistocene to Holocene, and of alluvial deposits of variable grain size. The soils of the internal areas, less extensive than those described above, are those that formed on a substrate of sandstones with alternations of marl and clay.

Much of the basin is used for agricultural purposes. Major crops and land uses receiving applications of nutrients and chemicals include cereals, vegetables and fruit orchards. Soils that support these land uses range from the loam to clay loam, in the northern portions of the basin, to the fine silty loams in the southern basin.

\subsection{Geo Database Implementation}

A spatial digital database for the study area was established through the assembly of various publicly available physiographic data sets (land use, soils, climate, depth to groundwater, elevation).

Such datasets characterised features considered to be directly or indirectly involved in the leaching process, thus characterising boundary conditions. Data was structured into feature datasets and raster datasets, in that both discrete and continuous data types were implemented in this study (Table 1). 
Table 1 Summary of the GIS datasets

\begin{tabular}{l|l|l|l}
\hline Feature & $\begin{array}{l}\text { Data } \\
\text { format }\end{array}$ & Spatial resolution & Data source \\
\hline Land use & Vector & $\begin{array}{l}\text { Digitised form 1:10,000 } \\
\text { scale }\end{array}$ & $\begin{array}{l}\text { INEA-Progetto } \\
\text { SIGRIA }\end{array}$ \\
\hline Soil texture & Vector & Cell size $20 \mathrm{~m}$ & $\begin{array}{l}\text { Basilicata region } \\
\text { Senise }\end{array}$ \\
\hline Soil profile depth & Vector & Cell size $20 \mathrm{~m}$ & $\begin{array}{l}\text { Basilicata region } \\
\text { Senise }\end{array}$ \\
\hline Precipitation (years) & Raster & Cell size $20 \mathrm{~m}$ & AdB \\
\hline $\begin{array}{l}\text { Temperature (year } \\
\text { mean) }\end{array}$ & Raster & Cell size $20 \mathrm{~m}$ & AdB \\
\hline Elevation & Raster & Cell size $20 \mathrm{~m}$ & SAFE-Univ. Basilicata \\
\hline Freatimetry & Raster & Cell size $20 \mathrm{~m}$ & AdB \\
\hline
\end{tabular}

Table 2 Land use classes from the original map are summarised into 10 main categories

\begin{tabular}{l|r|c}
\hline Land use & Number & Hectares \\
\hline Non-vegetated area & 1505 & 17.705 \\
\hline Forest & 10 & 0.524 \\
\hline Cereal & 445 & 10.794 \\
\hline Fruit tree & 1689 & 50.564 \\
\hline Leguminous & 39 & 0.624 \\
\hline Olive orchard & 456 & 4.206 \\
\hline Vegetable & 1003 & 10.959 \\
\hline Grass land and pasture & 16 & 0.660 \\
\hline Ploughed areas & 1083 & 17.816 \\
\hline Grape orchard & 229 & 3.131 \\
\hline
\end{tabular}

Data manipulation and spatial analysis were performed to finally produce output datasets as described in the previous table.

\subsubsection{Land Use}

Land use dataset, published within Progetto Sigria, INEA 2000, was used to describe cropped species at parcel level and furthermore to define the spatial extent of the whole GIS project in this work. Table 2 shows cropped surfaces in hectares summarised by aggregated land use classes.

Fruit orchards land use dataset, published within Progetto Sigria, INEA 2000, was used to describe cropped species at parcel level and furthermore to define the spatial extent of the whole GIS project in this work. Fruit orchards cover almost $44 \%$ of total study area, followed by ploughed areas covering $15 \%$, vegetables $10 \%$ and cereals $10 \%$. Non-vegetated areas, such as urban or water bodies, make up for $15 \%$. 
Soil data were originally acquired from regional geology agency in tabular format for 52 soil profiles sampled across the study area (see circles in Fig. 1. For each profile, a fictitious soil system was adopted, assuming the soil to be composed of only two layers, A and B, the first being superficial and $40 \mathrm{~cm}$ thick (this was the average depth of the first horizon for all the soil profiles and the latter reaching the water table). A fictitious soil profile was obtained for each real soil profile by averaging textural data with a weighted procedure using horizon depths as weights.

Data were then imported into GIS and spatial structure of sand, clay and silt contents, and depth measures were analysed with Exploratory Spatial Data Analysis (ESDA) tools, by means of classic statistical and geostatistical analyses. After interpolation, continuous surfaces for sand, clay, silt and soil profile depth were produced in raster format for both A and B soil layers (maps not shown).

Sand, silt and clay raster datasets were concurrently queried with a map calculator using a set of SQL statements, each defining a texture constraint for each soil class according to USDA classification system, in order to produce two final texture maps (Fig. 2), one for each fictitious soil layer.

a

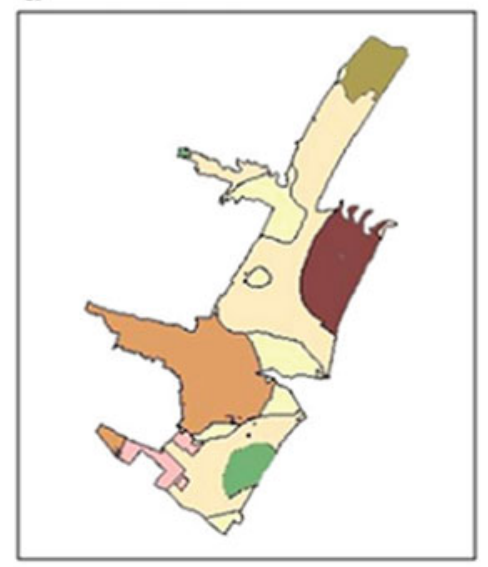

Logond

Texture map

A Layer

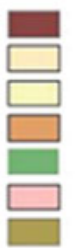
Clay
Clay loam
Loam
Silt loam
Silt clay
Silt clay loam
Sandy clay

b

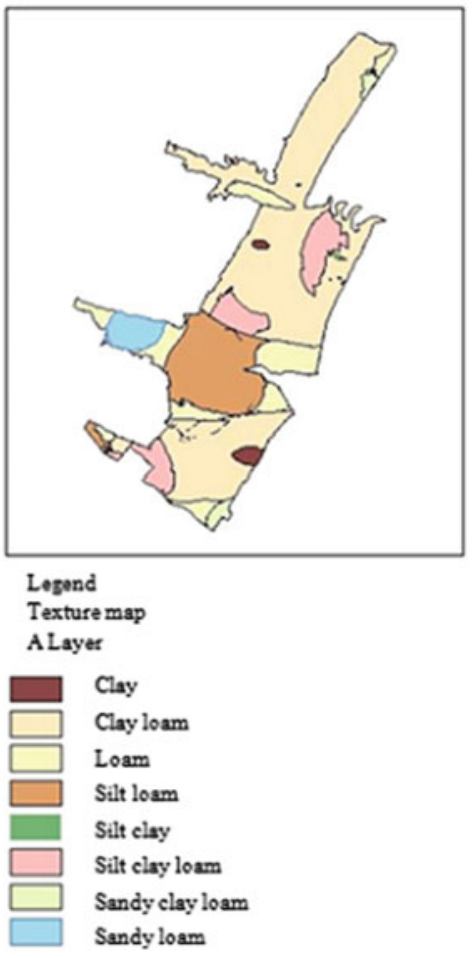

Fig. 2 Texture map for layers (a) and (b) 


\subsubsection{Precipitation, Temperature and Evapotranspiration}

Climate data on a daily basis for the 1999-2009 period for all the climatic stations localised in the area of interest were provided by Regional Agriculture Services. The Voronoi algorithm was used for spatial partitioning of the study area according to the subarea of influence of each rainfall station. The Voronoi cells for the area under study are shown in Fig. 3.

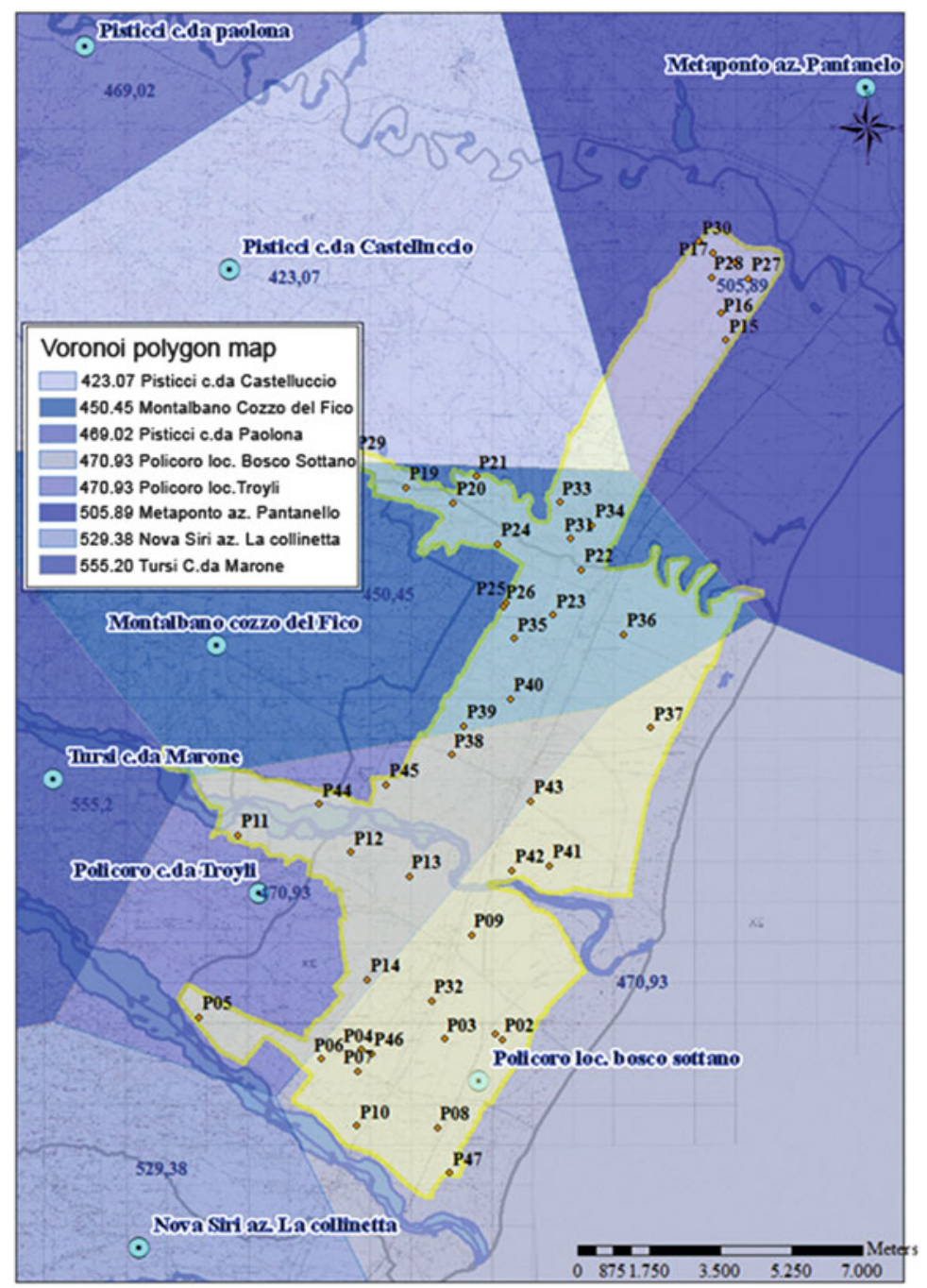

Fig. 3 Positions of meteorological stations and Voronoi polygons of the study area. Alphanumeric codes identify the soil profiles used for this study 


\subsubsection{Elevation}

Contour lines on IGM 1:5,000 base maps were digitised, and a triangulated irregular network was created from them and finally converted into a raster dataset. From elevation grid, slope grid was derived as well.

\subsubsection{Depth to Groundwater}

The laboratory of Soil and Contaminant Hydrology of the University of Basilicata provided tabular data for 192 measuring wells, 51 of which were located within the study area. Once imported into GIS as a point feature dataset, groundwater depth at measuring stations was interpolated using Kriging, thus resulting in a continuous surface (map not shown).

\subsection{Geoprocessing and Data Handling}

The role of GIS in this study was to provide hydrological modelling with a spatial database carrying all the necessary information for leaching assessment: textural class, soil depth, water table depth and net water recharge.

In order to achieve such goal, datasets carrying spatially distributed information of these data, collected as described above, were aggregated at homogenous soil units level on one common layer enabling further data manipulation and derived variable creation, such as water recharge.

Homogenous soil units (being areas characterized by sufficiently similar leaching behaviour) were defined intersecting soil texture information for layers $\mathrm{A}$ and $\mathrm{B}$ through geoprocessing tools, which finally resulting in a polygon feature vector dataset. Each polygon defines a combination of two overlaying textural classes; in all there were 31 possible texture combinations classes.

Finally zonal attribute transfer was then performed from land use, rain, freatimetry, temperature, slope and elevation datasets to soil unit feature dataset, in order to associate to each soil unit such spatially distributed information averaged for each polygon surface. Furthermore for each soil unit potential evapotranspiration (ETp) was calculated using the Thornthwaite formula (USDA 1975).

At this point the output spatial database was set up with all calculated, estimated and derived physical attributes related to each polygon representing an instance of a homogeneous soil unit. In Table 3 are shown three explanatory records out of the total 7,872 . Such database was implemented in hydrological modelling as discussed in the following section. 
Table 3 Spatial database for three explanatory records

\begin{tabular}{l|l|l|l|l|l|l}
\hline $\begin{array}{l}\text { Polygon } \\
\text { ID }\end{array}$ & $\begin{array}{l}\text { Texture } \\
\text { overlay }\end{array}$ & $\begin{array}{l}\text { Land } \\
\text { use }\end{array}$ & $\begin{array}{l}\text { Mean } \\
\text { depth } \\
\text { layer A }\end{array}$ & $\begin{array}{l}\text { Mean depth of } \\
\text { groundwater } \\
\text { table }\end{array}$ & $\begin{array}{l}\text { Annual } \\
\text { mean } \\
\text { ET }_{\mathrm{p}}\end{array}$ & $\begin{array}{l}\text { Annual net } \\
\text { water } \\
\text { recharge }\end{array}$ \\
\hline 1 & $\begin{array}{l}\text { Clay loam } \\
\text { on clay }\end{array}$ & $\begin{array}{l}\text { Fruit } \\
\text { tree }\end{array}$ & 0.628 & 26.238 & 900 & 623 \\
\hline 2 & $\begin{array}{l}\text { Clay loam } \\
\text { on clay } \\
\text { loam }\end{array}$ & $\begin{array}{l}\text { Olive } \\
\text { orchard }\end{array}$ & 0.611 & 15.682 & 1,099 & 1,261 \\
\hline $\begin{array}{l}\text { Clay loam } \\
\text { on clay } \\
\text { loam }\end{array}$ & $\begin{array}{l}\text { Fruit } \\
\text { tree }\end{array}$ & 0.595 & 11.024 & 988 & 1,340 \\
\hline
\end{tabular}

\subsection{Stochastic Development of $T F_{t b}$}

\subsubsection{Texture-Based Hydraulic and Solute Travel Time Distributions}

A large dataset of hydraulic properties was already available for the textural classes of the area. They were measured in the laboratory on undisturbed soil samples (490 samples) collected at the soil surface during several previous measurement campaigns.

Soil water retention was described by the unimodal $\theta(h)$ relationship proposed by van Genuchten (1980) and expressed here in terms of the scaled water content $\left(S_{\mathrm{e}}\right)$ as follows:

$$
S_{\mathrm{e}}=\frac{\theta-\theta_{\mathrm{r}}}{\theta_{0}-\theta_{\mathrm{r}}}=\left[1+\left|\alpha_{\mathrm{VG}} h\right|^{n}\right]^{-m}
$$

where $\alpha_{\mathrm{VG}}\left(\mathrm{cm}^{-1}\right), n$ and $m$ are curve-fitting parameters and $h$ the pressure head.

Mualem's expression was used to calculate relative hydraulic conductivity, $K_{\mathrm{r}}$ (Mualem 1976); assuming $m=1-1 / n$, van Genuchten (1980) obtained a closedform analytical solution to predict $K_{\mathrm{r}}$ at a specified volumetric water content

$$
K_{\mathrm{r}}\left(S_{\mathrm{e}}\right)=\frac{K\left(S_{\mathrm{e}}\right)}{K_{0}}=S_{\mathrm{e}}^{\tau}\left[1-\left(1-\mathrm{S}_{\mathrm{e}}{ }^{1 / m}\right)^{m}\right]^{2}
$$

where $\tau$ is a parameter accounting for the dependence of the tortuosity and the correlation factors on the water content and $K_{0}$ is the hydraulic conductivity at $h=0$.

For each soil sample a detailed particle-size distribution (PSD) was also available. PSD data were used as a basis for estimating soil water retention (and the corresponding parameters in Eq. (1) of soil horizons of each of the observation soil profiles by using the physico-empirical PTF approach proposed by Arya and Paris (1981). Hereafter, such an approach will be referred to as the AP approach. The 
original formulation based on a single optimisation parameter $(\alpha \mathrm{AP})$ was thus made more flexible by assuming a variable $\alpha \operatorname{AP}(h)$ with the pressure head $h$.

Arya et al. (1999) also derived an expression to compute $K(\theta)$ directly from the PSD, based on the same soil structure model leading to the $\theta(h)$ function. We opted for using the method only for estimating the saturated hydraulic conductivity. The whole hydraulic conductivity curve was estimated by using Eq. (2), with retention parameters and $K_{0}$ estimated by the AP method and setting $\tau=0.5$. A specific $\alpha \operatorname{AP}(h)$ curve was obtained for each of the textural class present in the investigated area. The measured hydraulic properties were partly (200 samples) used for the PTF calibration, by keeping the remaining data for the PTF validation.

In synthesis, site-specific PTF allowed estimating a complete set of hydraulic parameters $\left(\theta_{0}, \theta_{r}, \alpha_{\mathrm{VG}}, n, K_{0}\right.$ and $\left.\tau=0.5\right)$, for each of the textural classes found in the area. A Kolmogorov-Smirnov test showed that all the parameters were normally distributed. The mean and the covariance matrix for the five parameters (all but $\tau$ ) were computed for each of the textural classes encountered along the soil profiles. Thus, random field of the five parameters was produced with a Monte Carlo procedure from the correlated multivariate normal distribution for any textural classes by generating a vector $x$ of independent standard normal deviates and then applying a linear transformation of the form $x=\mu+L r_{n}$, where $\mu$ is the desired vector of means and $L$ is the lower triangular matrix derived from the symmetric covariance matrix $V=L L^{\mathrm{T}}$ decomposed by Cholesky factorisation. In other words, the procedure generated random field with correlated parameters by multiplying the lower triangular Cholesky decomposition of the covariance matrix with vectors, $r_{n}$, containing five $N(0,1)$ randomly distributed numbers and by summing up the result to the mean of the parameters. We recall that using the statistical moments of the parameters of the hydraulic functions for generating the random field to be used in Monte Carlo simulations implies the assumption that soil hydraulic variability can be described by the statistical distribution of such parameters. This widely used approach is conceptually simple and is based on the idea of approximating stochastic processes by a large number of equally probable realisations. In this study, 400 sets of equally probable hydraulic parameter realisations were generated for each of the textural classes.

As for solute transport, solute travel time distributions were deduced by applying the method proposed by Scotter and Ross (1994), which estimates breakthrough curves of a tracer at a given depth for a given soil starting with the hydraulic conductivity function of that soil. According to the transfer function model (TFM), the flux concentration at a depth $z, C^{\mathrm{f}}(z, I)$, given a time-varying flux concentration at the input surface $C^{\mathrm{f}}(0, I)$ is given by

$$
C^{\mathrm{f}}(z, I)=\int_{0}^{z} C^{f}\left(0, I-I^{\prime}\right) f^{f}(z, I) d I^{\prime}
$$

where $f^{\mathrm{f}}(z, I)$ is the steady-state travel time distribution (travel time pdf) defining the changes in the normalised concentration in the drainage as the cumulative drainage $I$ builds up. For steady-state flow conditions, $I=q t$, where $q$ is the 
steady-state flow rate and $t$ is the time. Scotter and Ross (1994) assumed a gravityinduced water flow, a conservative and nonreactive solute and a purely convective flow, thus ignoring any convective mixing of solute flowing at different velocities and the effects of molecular diffusion. With these assumptions, the $f^{\mathrm{f}}(z, t=I / q)$ for a pulse input of solute can be obtained as

$$
f^{\mathrm{f}}(z, t)=\frac{\mathrm{d} C^{f}(z, t)}{\mathrm{d} t}=-\frac{1}{q} \frac{\mathrm{d} K(\theta)}{\mathrm{d} t}
$$

For a log-normal distribution of the cumulative drainage (or of travel times) the analytical expression for the pdf is a log-normal density function

$$
f(I)=\frac{1}{\sqrt{2 \pi} \sigma I} \exp \left[-\frac{(\ln I-\mu)^{2}}{2 \sigma^{2}}\right]
$$

in which $\mu$ and $\sigma$ are the parameters of the log-normal pdf.

For the case of a stochastic-convective with log-normal distribution of travel time (CLT) model, if the $f^{\mathrm{f}}(z, I)$ is known at a given depth $z_{1}$, then the TFM model allows for scaling that pdf to a depth $z_{2}$ according to the equation

$$
f^{\mathrm{f}}\left(z_{2}, I\right)=\frac{z_{1}}{z_{2}}\left(z_{1}, I \frac{z_{1}}{z_{2}}\right) .
$$

This means that $z_{1}=z_{2}$ and $z_{2}=z_{1}+\ln \left(z_{2} / z_{1}\right)$. If, to the contrary, the transport process obeys to the advection-dispersion (AD) model, $z_{2}=0.5 z_{1}\left(z_{1} / z_{2}\right)$ and $z_{2}=z_{1}+\ln \left(z_{2} / z_{1}\right)+0.5 z_{1}^{2}\left(1-z_{1} / z_{2}\right)$.

For each of the hydraulic parameter random vectors obtained for each textural class, a corresponding fictitious breakthrough curve, $f^{\mathrm{f}}(z, I)$, at an arbitrary depth of $z=40 \mathrm{~cm}$ was calculated according to Eq. (4) for a solute pulse injection at the surface. An inert, non-adsorbed (a tracer) solute was selected for simulation purposes. In order to calculate the cumulative drainage $I$, an hourly inflow rate was calculated by assuming that all the net recharge (the rainfall infiltrated in the soil minus the evapotranspiration) was uniformly distributed over the year and that storage and surface run-off were negligible.

By simply averaging over the 400 simulated breakthrough curves $f^{\mathrm{f}}(z, I)$, an upscaled probability density function was obtained. Effective parameters $\mu\left(\mu_{\mathrm{ef}}\right)$ and $\sigma\left(\sigma_{\text {ef }}\right)$ at $40 \mathrm{~cm}$ for each textural class were estimated by fitting Eq. (5) to the upscaled curve.

\subsubsection{Upscaled Solute Travel Time Distribution for Textural Sequences}

By assuming the independence between two successive layers along a textural profile, assumed to consist of two layers $\mathrm{A}$ and $\mathrm{B}$, the mean $E(I, z=80 \mathrm{~cm})$ and 
variance $\operatorname{VAR}(I, z=80 \mathrm{~cm})$ were obtained by summing up the $E(I, z=40 \mathrm{~cm})$ and $\operatorname{VAR}(I, z=40 \mathrm{~cm})$ of the two textural classes for any textural sequence. The $E(I, z)$ and the $\operatorname{VAR}(I, z)$ were calculated as

$$
\begin{aligned}
& E(I, z)=\exp \left(\mu_{\mathrm{z}}+0.5 \sigma_{z}^{2}\right) \\
& \operatorname{VAR}(I, z)=\exp \left(2 \mu_{\mathrm{z}}+\sigma_{z}^{2}\right)\left[\exp \left(\sigma_{z}^{2}\right)-1\right]
\end{aligned}
$$

Once the upscaled $80 \mathrm{~cm}$ pdf was obtained, it was scaled with depth down to the water table according to the following hypothesis:

1. The transport mechanism in the second layer down to the water table is the CLT (the effective parameters were scaled according to the CLT model).

2. The transport mechanism in the second layer down to the water table is the CDE (the effective parameters were scaled according to the CDE model).

\section{Results and Discussions}

The outputs of the numerical simulations, carried out in a stochastic framework, were interpolated for producing continuous maps of the modal travel time, along with the corresponding uncertainty levels. Modal travel times for each of the textural sequences and for both the assumed transport mechanisms are synthesised in the maps in Fig. 4a, b; they exhibit remarkable differences in terms of travel time estimations for same soil textural classes due to the underlying transport approaches and soil layer conceptualisations.

Independently on the mechanism assumed, the spatial variability of textural layers was a major factor influencing the field water and solute transport in alluvial soils. Results showed large differences in the magnitude of the different travel times and related uncertainties among different profiles. The lower or higher vulnerability was found to be mainly related to the average silt content of the soil profiles. Higher travel time uncertainty was mainly related to the clay content in the range $20-40 \%$.

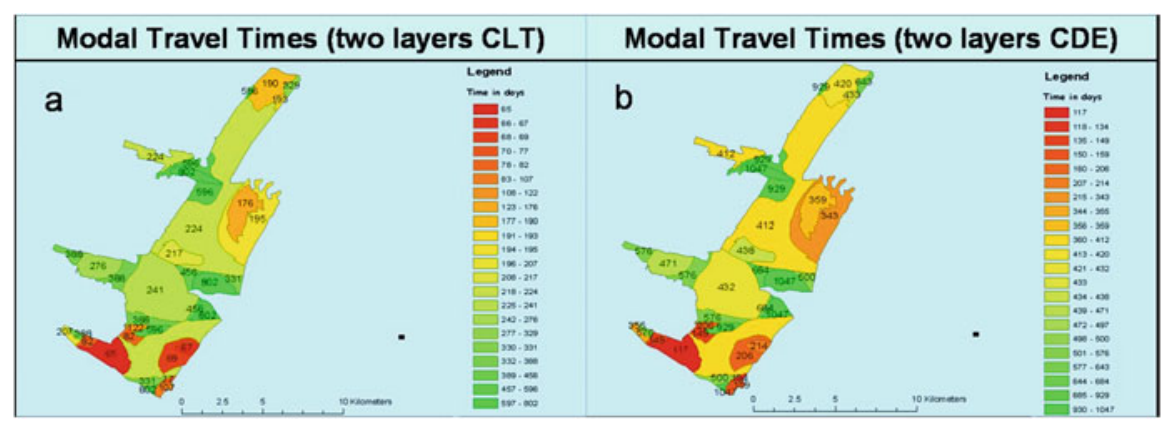

Fig. 4 (a) Modal travel time map for CLT process; (b) modal travel time map for AD process 
Fig. 5 Vulnerability risk for land use classes

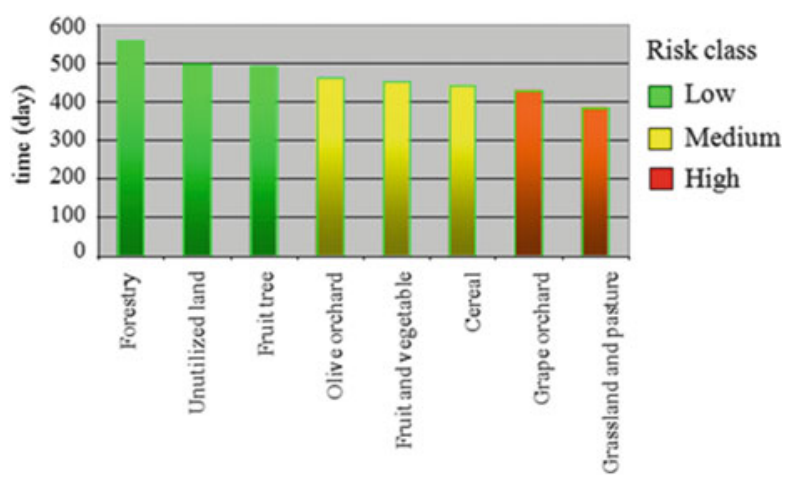

As for the CDE mechanism, travel times are generally higher than for the CLT by an average of $88 \%$, a minimum of $30 \%$ (loam on loam) and a maximum of $220 \%$ difference (silty clay on clay). Highly vulnerable areas, being characterised by a shorter travel time, showed to be more subject to estimation value fluctuations depending on the transport mechanism compared to more protected areas.

Of course, the local travel time should be interpreted according to the specific local conditions, especially in terms of land use, crop, water table depth and rainfall. Referring to CDE transport mechanism, travel time values were reclassified using natural breaks classification method into three main vulnerability classes: low risk, medium risk and high risk. In figure 5 is showed a comparison between land use classes versus vulnerability risk classes, using a spatial join constraint. Very low vulnerability resulted associated with areas not subject to intensive agrochemical inputs such as forest, to unutilized areas and to fruit tree orchards; fruit and vegetables together with olive orchards and cereals classes showed an average medium risk. Finally grape orchards and grassland/pasture land are associated with high risk.

Spatial distribution, fragmentation and perimeter to area ratio of land use patches were taken into account to ensure data homogeneity during generalisation of travel times and subsequently land use class risk rankings (Batty and Longley 1994).

\section{Conclusions}

All the past efforts to evaluate solute travel times to groundwater at the regional scale have frequently been hindered by the problem of how to account for the variability of soil layering. Past studies tended to decompose a profile into several (usually three to four) functional horizons and assumed that they are identical within a certain area when the water flow and the solute transport are modelled. This method may be suitable for some genetic soils that consist of intrinsic genetic horizons and do not vary significantly in the thickness of every horizon within a certain area. However, for alluvial soils, which are widely distributed in the alluvial 
plain investigated in this paper, the textural layering is very complex. Accordingly, to accurately quantify the solute transport process at regional scale, we took the spatial variability of textural layers explicitly into account. Information on soil textural profiles was coupled with a texture-based transfer function solute transport model to conduct a stochastic analysis of the solute transport in the Metaponto area (Basilicata region, South Italy). The aim was to assess the effect of spatial variability of textural layers on the solute travel times, along with their probability distributions. The strength of the methodology becomes apparent especially if compared to qualitative models that, while being the most common solution for regional studies, rely uniquely on empirical conceptualisations of chemical leaching processes and give as outputs only general qualitative indication rankings without quantification of risk in terms of travel times.

Open Access This chapter is distributed under the terms of the Creative Commons Attribution Noncommercial License, which permits any noncommercial use, distribution, and reproduction in any medium, provided the original author(s) and source are credited.

\section{References}

Arya LM, Paris JF (1981) A physicoempirical model to predict the soil moisture characteristic from particle-size distribution and bulk density data. Soil Sci Soc Am J 45:1023-1030

Arya LM, Leij FJ, Shouse PJ, van Genuchten MT (1999) Relationship between the hydraulic conductivity function and the particle-size distribution. Soil Sci Soc Am J 63:1063-1070

Batty M, Longley PA (1994) Fractal cities: a geometry of form and function. Academic, London

Comegna A, Coppola A, Comegna V, Severino G, Sommella A, Vitale CD (2010) State space approach to evaluate spatial variability of field measured soil water status along a line transect in a volcanic-vesuvian soil. Hydrol Earth Syst Sci 14:2455-2463

Coppola A, Comegna A, Dragonetti G, Dyck M, Basile A, Lamaddalena N, Kassab M, Comegna V (2011) Solute transport scales in an unsaturated stony soil. Adv Water Resour 34:747-759. doi:10.1016/j.advwatres.2011.03.006 9

Coppola A, Dragonetti G, Comegna A, Zdruli P, Lamaddalena N, De Pace S, Simone L (2014) Mapping solute deep percolation fluxes at regional scale by integrating a process-based vadose zone model in a Monte Carlo approach. Soil Sci Plant Nutr. doi:10.1080/00380768.2013. $855615 \mathrm{~N}$

Corwin DL (1996) GIS applications of deterministic solute transport models for regional-scale assessment of non-point source pollutants in the vadose zone. In: Corwin DL, Loague K (eds) Applications of GIS to the modeling of non-point source pollutants in the vadose zone. Soil Science Society of America, Madison, WI, pp 69-100

Corwin DL, Loague K, Ellsworth TR (1997) GIS-based modeling of nonpoint source pollutants in the vadose zone. J Soil Water Conserv 53:34-38

Jury WA, Roth K (1990) Transfer function and solute movement through soil: theory and applications. Birkhauser, Basel, p 26

Mualem Y (1976) A new model for predicting the hydraulic conductivity of unsaturated porous media. Water Resour Res 12:513-522. doi:10.1029/WR012i003p00513

Scotter DR, Ross PJ (1994) The upper limit of solute dispersion and soil hydraulic properties. Soil Sci Soc Am J 58:659-663 
Stewart IT, Loague K (2003) Development of type transfer functions for regional-scale nonpoint source groundwater vulnerability assessments. Water Resour Res 39(12):1359. doi:10.1029/ 2003WR002269

USDA (1975) Soil taxonomy: a basic system of soil classification for making and interpreting soil surveys. Agr Handb 436. U.S. Department of Agriculture, Washington, DC

van Genuchten MT (1980) A closed-form equation for predicting the hydraulic conductivity of unsaturated soils. Soil Sci Soc Am J 44:892-898 